\title{
Cidades-experimentações: para inscrição numa (est)ética da aprendizagem enquanto acontecimento
}

\author{
Margarete Axt, ${ }^{I, \star ~ P a u l a ~ M a r q u e s ~ d a ~ S i l v a, ~}{ }^{I}$ Joelma Adriana Abrão RemiãoI \\ ${ }^{I}$ Universidade Federal do Rio Grande do Sul, Porto Alegre, RS, Brasil \\ ${ }^{I I}$ Universidade Estadual do Centro-Oeste, Irati, PR, Brasil
}

\begin{abstract}
Resumo
Este texto, ao adentrar os muitos planos traçados por uma história de pesquisa e formação esculpida numa zona de interferência com a filosofia, em especial com Gilles Deleuze, Henri Bergson e Mikhail Bakhtin, discorre sobre como a temática da cidade vai se tornando expressiva em seu devir experimentação, sugerindo um efeito-labirinto de nós em rede-de-nós, que não para de se bifurcar e, paradoxalmente, também não para de, em nós, se condensar como um efeito-cidade-em-nós. Um encontro (est)ético com cidades construidas por crianças no entrelaçamento do currículo programático escolar e a cidade do cotidiano, tecendo-se em composições narrativas.
\end{abstract}

Palavras-chave: Cidade-Experimentação; Pesquisa-formação; Narratividade criadora; Prática docente; Educação básica.

\section{Experimentation-cities: for enrolment in a learning aesthetic as an occurrence}

\begin{abstract}
This text, upon entering the various plans traced by a history of research and development and sculpted in a zone of interference with philosophy, specifically with Gilles Deleuze, Henri Bergson and Mikhail Bakhtin, addresses the manner in which the theme of the city becomes expressive in its becoming experimentation, suggesting a knot of maze-effect in a network-of-knots that does not stop splitting, while paradoxically, it also does not stop condensing, in us, as a city-in-us-effect. An aesthetic encounter with cities built by children in the entanglement of the academic curriculum with everyday city life, thus weaving narrative compositions.
\end{abstract}

Keywords: Experimentation-City; Research-development; Creative Narration; Teaching practice; Elementary education.

\section{As cidades-experimentações das crianças e o efeito- cidade-em-nós!}

Talvez do mundo só reste um terreno baldio coberto de imundicies e o jardim suspenso do paço imperial do Grande Khan. São nossas pálpebras que os separam, mas não se sabe qual está dentro e qual está fora (CALVINO 1990a, p. 96).

São infindos os humores e as faceirices dessas cidades, agenciadas à moda de um efeito-cidade-em-nós, no plano de composição das narrativas ${ }^{1}$ que se seguem! $!^{2}$

\footnotetext{
^Endereço para correspondência: Universidade Federal do Rio Grande do Sul, Faculdade de Educação, Departamento de Estudos Especializados. Av. Paulo Gama, 110 - Campus Centro Prédio 12105 (Cinted), sala 338. Centro - Porto Alegre, RS - Brasil. CEP: 90046900. E-mail: maaxt03@gmail.com, paulilinha1976@yahoo.com.br, joremiao@gmail.com

Operamos com a narrativa neste sentido dado por Costa (2014, p. 551), quando afirma que a narrativa se produz enquanto uma estratégia que acolhe elementos de experiência os quais fazem parte da constituição do campo de pesquisa e/ou intervenção: sensações, afetos, experiências singulares, possibilidades nebulosas, tensões incoerentes, etc. Para o autor esta nuvem virtual de sutilezas sustenta a concretude dos nossos encontros com o mundo, abrindo passagem para políticas de hibridização entre as ciências e as artes na produção de conhecimento.

${ }^{2} \mathrm{As}$ composições narrativas que seguem foram produzidas livremente por nós enquanto efeito de nossas escutas, num encontro (est)ético com cidades construídas por crianças e por elas narradas em suas escritas, no Ensino Fundamental (3 séries e $4^{\circ}$ e $5^{\circ}$ anos), de escolas públicas municipais no interior do RGS, conveniadas com o Projeto Civitas, e das quais tomamos ciência através de visitas locais às salas de aula e da leitura dessas narrativas; e também através de relatos feitos por pesquisadores-formadores e por professores dessas escolas, onde a proposta de pesquisa-formação do Projeto Civitas se desenvolve/u, citados no início de cada narrativa. Apoios CNPq, MEC-SESu, CAPES, FINEP, UFRGS, SMEDs dos Municípios conveniados, ao longo dos anos, desde 2002-atual.
}

a) "Pereringombola" (SELLI; AXT, 2014), ${ }^{3}$ por exemplo, deve seu nome à confluência do rio $\mathrm{Pe}$ rerin com o lago Gombola, componentes da bacia hidrográfica que define a geografia da região; é uma cidade de sons, cheia de personalidade, na qual a paisagem sonora combina-se com a ecologia ambiental, dando lugar de destaque às árvores - os plátanos; estes, por sua vez, detêm o segredo da energia (alternativa), captada através das suas folhas e distribuídas por antenas (como as de celulares). É por isso que nessa cidade não há outono, apenas verão, inverno e primavera! Os moradores dificilmente adoecem, pois praticam uma alimentação balanceada; e a água é captada diretamente do rio, que até mesmo tem valor medicinal, uma vez que os cuidados com a preservação do ambiente o protegem da poluição. Se alguém entender que está na hora de morrer por estar muito velho, pode "virar outra coisa": flor, borboleta, árvore, "dando conta de uma experimentação do pensamento em torno de valores vitais, derivada não apenas de um posicionamento ético de responsabilidade ambiental e de ternura com o outro, mas mais uma vez, de uma cosmovisão poético-estética de constituição existencial" (SELLI; AXT, 2014, p. 238); uma cidade altamente tecnologizada, mas em que o "modo formiga"

\footnotetext{
${ }^{3}$ Pelas características de resgate de uma história de pesquisa e formação, de que se reveste este texto, muitas referências serão feitas às publicações do grupo, em vista do trabalho conceitual, laborado em sua artesania, que acompanhou a duração do Projeto Civitas, no tempo.
} 
de pensar econômica-capitalisticamente acaba por ceder lugar, ao longo de um ano letivo, a um "modo cigarra" de viver na duração criadora, este tempo bergsoniano que exercita uma relação inventiva e poiética ${ }^{4}$ com a vida em seu devir... Uma cidade-cigarra!, que quer dobrar a tecnologia e o ethos capitalístico sobre si, num jogo de forças, imprimindo-lhe uma (est)ética do viver, nascida na potência espinosista da alegria e dos "bons encontros" (DELEUZE, 2002)...

b) Já "Candeuru" (KRUG, 2008) nasceu despretensiosa como vila, com uma só rua... e eis que deveio cidade, saindo do seu lugar periférico no canto da sala, e ocupando o espaço central da sala de aula, onde teimou em ficar o ano todo... cheia de estilo, entre placas de isopor, casas e prédios já construídos, árvores plantadas e hortas, não perdeu a memória de estar vila, e um grande desafio foi o de ultrapassar aderências resistentes e mudar o plano diretor dessa que queria devir-cidade: para poder crescer cidade, a vila dedicou-se, intensiva, a resolver como a rua única (típica de vila), poderia se desdobrar em novas bifurcações viárias, para esparramar-se ao longo das novas placas de isopor anexadas: eis aí o conceito de bifurcação, uma questão de física, no melhor sentido da palavra, que não dispensou em momento algum exercícios aritméticos e medidas geométricas utilizando réguas e outros apetrechos, ou divagações filosóficas que dessem contornos à noção... um esforço concentrado para apresentar e pesar pontos de vista, confrontar hipóteses, testá-las, experimentando a cidade-rua, marcando-a enquanto cidade-corpo... engenhando um coletivo pensante...

c) Há também a cidade (MARTINS, 2009) que foi "varrida do mapa" (ou da sala de aula), pela enchente do município, desmanchando lares e personagens-avatares (as crianças-moradoras): uma catástrofe que abriu ao filosofar sobre a fragilidade da vida e a constância da morte, à elaboração de perdas de entes queridos como avós e amigos: uma cidade-filósofa que fez corpo com o cemitério, com a imigração de novos habitantes para ser reconstruída, a diversidade étnica, e com estudos de prevenção de catástrofes naturais... ah! e como não dizer: povoar a memória dos "novos" moradores com as histórias da cidade destroçada, assim como contar os novos acontecimentos da cidade-renascida, tornou-se um compromisso com o outro... quantas histórias! Quantas escritas e quantas leituras!...

d) E a cidade digital (MARTINS, 2009) dos ETs, os quais tinham uma língua diferente da dos humanos, obrigando a múltiplos exercícios de tradução e conversão, na tentativa de estabelecer o entendimento mútuo, que levasse a uma cooperação solidária em defesa do planeta assim como do sis-

\footnotetext{
${ }^{4}$ Termo grego poiesis, significando criação, de onde deriva a palavra poesia, fo reatualizada pelos chilenos Maturana e Varela no conceito de autopoiese, central na proposta desses autores para uma biologia do conhecer na década de 1970, e potencializada por Guattari (1993) enquanto um operador de diferença.
}

tema planetário, ambos ameaçados de extinção!! Obviamente, os humanos também habitavam uma cidade bem-humorada, erigida em papelão, que não abria mão de ocupar metade do espaço da ampla sala. Contam as conversas por "telefone sem fio", que as brigas, os gritos, os problemas de indisciplina e as desaprendizagens abandonaram o lugar (como já ocorrera em outros lugares), para dar espaço a um novo plano comunicacional (local-global), em que o molecular exercitou uma maquínica dos corpos e de suas enunciações, cujo efeito fez transbordar as cidades-experimentações na sala de aula: "fora" e "dentro" se tornaram difusos em suas fronteiras: expressão coletiva e singularidade ganharam potência, em mútua inter-relação, sem que um termo dominasse o outro: o burburinho, agora calcado na alegria de um coletivo em trabalho de construção, se fez instituinte na conjuração de fluxos criativos e de cooperação solidária, trazendo de volta os processos de aprender que aí, nas cidades-experimentações, fizeram rizoma: a aprendizagem assumiu o comando, estendendo linhas de virtualização e potência em direção ao outro, eu/não-eu entrando em estado de reverberação vibrante: cidades-planetas, cujas autoridades foram entrevistadas na emissora de rádio local da cidade costumeira de todos nós: e que literalmente receberam a visita de prefeito e vereadores dessa cidade do cotidiano costumeiro de todos nós, os quais sentaram em reunião de planejamento (sobre a escola e sobre a cidade, qual cidade?) com prefeitos e políticos das tais cidades-planetas das experimentações! Cidades da imaginação que voltaram a vibrar no tempo por ocasião das matrículas, quando os pais das novas turmas de $4^{\circ}$ ano queriam todos matricular suas crianças na turma do "projeto das cidades"!

e) Ainda, uma cidade "Reino do Sol" (KREUTZ, 2009) que, tendo iniciado como sítio na zona rural habitado por imigrantes, acabou por traçar o plano do cooperativismo, em que pese os múltiplos fluxos econômico-capitalísticos. Uma cidade-cooperativa, catalisando os fluxos migratórios, étnico-culturais e até legais-penais. Abatida por um assassinato que ganhou as manchetes da cidade costumeira de todos nós, a cidade-cooperativa também teve seu crime "acidental". Novamente, num transbordamento recíproco dentro-fora que borrou as fronteiras, a juíza da cidade do cotidiano costumeiro de todos nós acedeu a um convite da cidade-cooperativa (esta muito ciosa de si!) para debater os direitos humanos e seus deveres, os vários rostos da violência, os modos de funcionamento dos fluxos da justiça: tudo isso, rendendo a dramatização e a encenação de um julgamento na cidade-cooperativa, promulgação de leis... a última notícia que ouvimos a respeito dessa cidade-lei era a de que seus habitantes, política e eticamente responsáveis, estavam de maneira absoluta de- 
dicados à "questão do aquecimento global. Uma equipe tem estudado os efeitos do aumento da temperatura da terra" (KREUTZ, 2009, p. 162).

f) Uma cidade (informação verbal) ${ }^{5}$ abortada em seu devir criativo capitulou no encontro com "paixões tristes" (DELEUZE, 2002), numa melancólica evidência do contraexemplo... suas crianças ousaram devir a cidade nos fluxos da "boca de fumo", da violência doméstica e da zona (zona de prostituição). O que poderia ter sido um bom encontro no plano de uma arquitetônica da vida e dos valores vitais sofreu um corte abrupto! Linhas de criação são frágeis, diz Deleuze (1996), não resistem aos moralismos, aos cortes segmentares da molaridade unívoca que define e separa bem e mal, beleza e feiura, verdade e erro... como já ouvimos dizer, os há em todas as plagas, aqueles que insistem em ser "guardião da cidade das Esmeraldas", obrigando a todos e cada um, que porventura queiram adentrar a cidade dO Mágico de OZ (BAUM, 2001), a portar os óculos de lentes verdes (e que não podem ser retirados, a não ser que o sejam pelo mesmo guardião, e só quando deixam a cidade), assim como aconteceu com Dorothy, o Espantalho, o Homem de Lata, o Leão e até o cachorrinho da menina... seria isso uma garantia "objetiva" de que todos estivessem exatamente na "mesma" cidade (vale dizer, de um modo triste, carente de sentidos vitais), só vissem as "mesmas" coisas (univocamente) e não tivessem abaladas suas crenças (de verdade) sobre uma cidade ser de "esmeraldas"?

g) Outra cidade (SOUZA, 2013), muito vaidosa, usinou uma planta subterrânea de eletricidade urbana, para deixar-se mais bela, livre de poluição visual, e também para que as árvores não precisassem ser podadas... cidade-paisagem, que fez corpo com os estudos sobre redes de distribuição e produção de energia elétrica, provocou um bom encontro espinosista com eletricitários que reparavam um transformador em frente à escola da cidade costumeira de todos nós, reverberando em processos de adensamento da noção de energia!

h) Mas e a "Cidade das Janelas"? Ou a cidade "Terra do Nunca"? (REMIÃO; SILVA; AXT, 2014). Cidades narradas pelas professoras e as crianças, tendo por suporte tecnologias variadas - arquitetura em papelão, desenho em papel/cartolina, fotografia, verbalizações orais e escritas em cadernos de anotações físicos ou digitais - umas tecnologias se desdobrando em outras, à moda rizoma, maquinando duplos com vida própria, simulacros... para contarem histórias - encontradas e desencontradas - que dizem de uma enunciação coletiva... O que será que não está à disposição na cidade costumeira de todos nós e que maquina o engendramento de uma cidade "Terra do Nunca"? Que desejos escondidos, não enunciados, aí lutam

${ }^{5}$ Relato de K. Souza, em 2011.

Fractal, Rev. Psicol., v. 28 - n. 2, p. 231-241, 2016 por visibilidade, cavando no socius da cidade-utopia um modo de se fazerem presença, e assim poderem catalisar o coletivo dessa polis imaginante numa vontade política de investimento em possibilidades (est)éticas do sentido existencial? Cidades para morar e viver... Assim também a Cidade das Janelas, ou cidade-janela, que passa à existência pelos desenhos e fotografias de um grupo de crianças e professora: do território fixo e costumeiro da sala de aula, elas passam a fabricar janelas para espiar a cidade do cotidiano de todos nós, num devir nômade da própria sala de aula, esta agora também aderida ao virtual: cidade-nômade, multiplicidade rizomática que se tece em meio a histórias de imagens e de escritas fazendo elo com a cidade de todos nós, num delírio da imaginação, que aprende a compor, a um só e mesmo tempo, com a rigidez estratificada das rotinas do costumeiro de todos nós, a dureza molar de um currículo programático escolar e a fantasmática desejante de um coletivo em suas expressões de singularidade.

Cidades de vampiros, de zumbis, de bruxas ou de fadas... cidades de insetos, de monstros, cidade-cigana... São incontáveis as cidades usinadas nestes mais de dez anos de existência do Projeto Civitas ${ }^{6}$ e incontáveis os seus atributos: cidades que têm personalidade, cidades que secretam humores, sejam eles alegres, tristes, dramáticos... cidades faceiras, estilosas, vaidosas... cidades-filósofas, ciosas de si, cidades-paisagem, cidades-planetas, cidades-utopia, cidades-cigarra, cidades-cooperativas, cidades-lei, cidades-nômades, cidades-corpo, cidades-tecnologia, cidades-linguagem, cidades-pensamento...

Não importam os nomes ou os atributos dessas cidades: como quer que as chamemos, estendem-se, como em eco longínquo, às cidades invisíveis de Italo Calvino (1990a): cidades intensivas desse aqui-agora que talvez jamais se dessem a ver-dizer não fossem os projetos coletivos agenciados entre crianças e educadores; cidades que vão se fazendo consistentes somente aos poucos, ao longo de um ano inteiro, no fluxo criador de um tempo $a$ la Bergson (2006), que dura-passando, descolando com lentidão das coisas e das representações pré-construídas pelo olhar e pela linguagem... descolando da instantaneidade dos eventos informacionais... descolando do moralismo domesticador do isto-é-não-é, isto-pode-não-pode; cidades que labutam para instaurar visi/dizibilidades particulares a cada coletivo, cada microato arquitetado pelo agir individual-coletivo, reverberando em sentido-acontecimento aberto a novas possibilidades, fazendo marca enquanto modo-rizoma de pensar, de ver-narrar; de experimentar.

\footnotetext{
${ }^{6} \mathrm{O}$ Projeto Civitas tem, tanto nos processos dialógicos (reverberando uma ética-estética bakhtiniana, em relação de solidariedade), como nas operações cartográficas (dizendo de uma filosofia da diferença deleuzo-guattariana), o seu dispositivo de "intervenção" (BAREMBLITT, 1998). Esta prática, pelas características enunciativas relacionais-dialógicas a ela imanentes (e cujos fluxos a cartografia se propõe seguir), se constitui privilegiadamente como "in(ter)venção" (AXT; KREUTZ, 2003), considerada a intenção de realce à natureza inventiva e única de cada intervenção em determinado campo de realidade, assim como de cada enunciação singular que a acompanha em sua disposição de sentido por mútua afetação.
} 
Lazzarotto (2012) alerta que, ao experimentar, não basta apenas entregar-se à experiência, mas trata-se principalmente de criar um modo de nela permanecer em processo, o que solicita a invenção. Para Axt (2013), a invenção em se fazendo por dentro, na duração do tempo, deixa-se a cavaleiro no próprio tempo, deixa-se devir: ela ainda refere como Deleuze (1997) fala do devir enquanto aquele processo que se faz a si no fluxo, em meio à contingência da vida, que não pretende alcançar determinada forma, uma identidade, mas que vai ao encontro de uma zona que, em lhe sendo vizinha ou próxima (o próximo passo), todavia lhe é indiscernível, desconhecido destino (vazio em aberto). Não se trata de futuro, devir e futuro se distinguem, pois que futuro planeja-se, esquadrinha-se. Fuganti (2012, p. 75) ressalta essa condição do devir, como "potência do acontecer, diferindo de si, sem jamais confundir-se com o estado resultante dessa mudança". Queremos enfatizar, com Axt (2013, p. 185-186) que o devir

encontra-se sempre entre o que já somos - passado presentificando-se - e o que ainda não somos - presente passando. $\mathrm{O}$ devir é sempre encontro, encontro com aquilo em que estamos nos tornando, com o incompleto em nós, a incompletude à espreita de completar-se [...]. As séries 'completude do que já fomos' e 'incompletude do que ainda não somos' não cessam de entrecruzar-se, tensionando as forças da criação e dando a ver a potência em sua multiplicidade [...].

As cidades, então, vão muito aos poucos se constituindo expressivas em seu devir experimentação, pondo-se e dispondo-se es-praia-das, para aí, nessas areias moventes e sempre lisas das praias estendidas em plataformas de isopor ou papelão ou ainda telas digitais, se comporem em linhas de fuga e lançarem-se a ser cidades...

Em todo o caso, em cada praia e seu devir cidade, trata-se sempre do pensamento, olhando à frente em ação criadora, microatos avançando ousados ao que está por vir, para, em estranhos arabescos, comporem-se híbridos com sopros de ventos imaginantes e impulsos de mar movente, encontro desassossegante das areias-partículas com a eterna estrangeiridade exilada dentro de si - mistura promíscua dos sentidos em fluxo, para, sempre de novo, deixar de ser o que parecia tão certo que era...

Mas é também neste um mesmo movimento criador que o pensamento volta sobre si, no esforço de atualizar uma memória em trabalho contínuo de se reinventar, dobrando-se com este aqui-agora das intensidades afectivas, perceptivas e motoras, para fazer corpo com o solo praiano sempre virgem das plataformas dessas cidades; e fixar um algo, seja nas edificações que vão sendo erigidas, seja nas imagens, nos sons, nas falas e nas escritas das histórias que vão sendo fabricadas, neste sempre-presente das expressividades em sua precariedade, sugerindo um efeito-labirinto de nós em rede-de-nós, que não para de se bifurcar; e, paradoxalmente, também não para de, em nós, se condensar como um efeito-cidade-em-nós...

Em cada cidade, uma experimentação do pensamento que luta para avizinhar-se desse sempre virgem dos areais das plataformas, desenhando rastros (precários e inacabados) a consolidarem interessantes combinações, modos flexíveis de se estar cidade: cada cidade-experimentação lembra o que Guattari (1993) pontua como subjetivação do espaço.

Trata-se, para nós, neste texto, de ir e vir por entre os muitos planos traçados por uma história de pesquisa, em aliança com a formação, nas suas acoplagens com salas de aulas ou outros espaços educativos (SILVEIRA, 2014; AXT; MARTINS, 2008), para perscrutar (e reatualizar), nestes entreplanos do Projeto Civitas, o que se inscreve como "praia que se espraia" para a experimentação (de cidades); e, simultaneamente, em coexistência paradoxal, apreender o que se inscreve como cidade, devindo "lugar" e também "passagem" para o gesto expressivo; e enfim, inquirir como e onde se produz o expressivo, apresentando-se como expressivo-novidadeiro.

Como responder dialogicamente (sem cair no lugar comum das explicações) a essas cidades-experimentações? Cidades imaginárias de crianças, medradas por entre as fímbrias de uma política de pesquisa e formação, entrelaçadas ao currículo programático escolar e à cidade do cotidiano costumeiro de todos nós! Entendemo-las as cidades-experimentações - antes como vozes em engendramento, que vão se fazendo corpo, num espaço e horizonte, no próprio ato de gestar da matéria expressiva; e que vão se compondo substantivas, por entre dissonâncias e divergências de um coletivo em burburinho, sintonizado com uma espécie de alegria primaveril, mas mais a um modo contemporâneo Stravinsky de sagração da primavera, do que ao de um clássico Vivaldi...

\section{As cidades-experimentações como efeito-cidade-em-nós}

As cidades também acreditam ser obra da mente ou do acaso, mas nem um nem o outro bastam para sustentar as suas muralhas. De uma cidade, não aproveitamos as suas setenta e sete maravilhas, mas as respostas que dá às nossas perguntas (CALVINO, 1990a, p. 44).

Cidades-experimentações não têm um dever (moral) de nascer expressivas ou criadoras de pensamento: nascem como podem, ora mais representacionais, ora mais moralistas, ora como apenas mais uma tarefa sem sentido, ou cidade-maquete com prazo de validade.

Mas também há aquelas às avessas, que desde logo têm uma profunda ambição de se insinuarem como cidade-invenção, mesmo se em inelutável coexistência com as molaridades do costumeiro e em meio a ele (já que não se ouviu falar ainda em invenção "pura", a não ser a do tempo que, em seu devir, ou é invenção ou não é nada, como lembra o aforismo bergsoniano). Assim como as tartaruguinhas precisam pela praia espraiar para lançarem-se ao mar, inventando um trajeto numa mise-en-scène com a vida no seu-acontecendo, cidades-experimentações precisam lançar-se a ser cidade...

Há que iniciar engenhando linhas que se lancem em busca de formas (também nunca formas puras - mais provável!, que parece que só as há em coexistência!): "protoformas" (GUATTARI, 1993), fazendo corpo híbrido com matérias-conteúdos-relações, e em que as possibilidades 
imaginativas vêm misturadas às estratificações do ver-dizer (dos significados instituídos, cristalizados e estáveis): é quando os agenciamentos em modo experimentação podem, ou sucumbir ao costumeiro, ou, ao contrário, resistir em seu processo imaginante, permanecendo experimentação, para sempre devir-cidade, tensionando materialidades em sua expressividade emergente, gestante...

Nascer cidade, portanto, não garante nada, seja do jeito que for! Na continuidade, há que habitar a cidade no seu tempo-duração, arrancá-la ao solo endurecido e estratificado das palavras de ordem, do bom senso e do senso comum, as ideias incorporando este devir-cidade. A cidade-rede-em-nós se presta a esta operação de passagem!

Entre processos cognitivos que, em sua dinâmica, podem transformar informações estáticas em conhecimento-saberes (em relação) e processos imaginativos que, em seu movimento de colher e combinar variedades, virtualizam o real e o inserem, criadoramente, em leque de novas composições sempre por vir, a cidade-rede pode inventar possibilidades, conectando objetos, fatos, pessoas, mundos, reconectando-os em outras vizinhanças... relações de multiplicidade em modo de nós, forçando em uma certa desejada precisão, mas enquanto acompanhada de também uma certa alegria imaginante!

Dias (2012, p. 129) sublinha, com relação ao conceito imaginação, que: "se imaginar está posto como possibilidade de transformação, esta é invenção". O Projeto Civitas trabalha com o conceito na mesma ótica, afirmando "uma virtualidade em movimento movendo-se junto com o viver em processo, podendo juntar fragmentos que nunca estiveram juntos, para produzir novas composições e visibilidades a partir desses heterogêneos" (AXT, 2014, p. 16-17).

É neste sentido que, numa cidade-rede, o mundo pode ser compreendido à maneira de Gadda (escritor contemporâneo, que concebe seus romances, para além dos enredos, em meio a vastos conhecimentos enciclopédicos, numa linha contínua entre arte e ciência), ou seja: “como um rolo, uma embrulhada, um aranzel, sem jamais atenuar-lhe a complexidade inextrincável [ou] a presença simultânea dos elementos mais heterogêneos que concorrem para a determinação de cada evento" (CALVINO, 1990b, p. 121).

É desse aranzel de coisas e estados de coisas que tipificam as cidades do cotidiano (em mistura com o currículo escolar, com informações-comunicações, com ficções e com afecções, sem deixar de fora esse indiscernível do querer latente), que um coletivo começa a agenciar uma cidade. Em outras palavras, pura "vontade de acontecimento" (BAKHTIN, 2002a), concentrando um valor ético-axiológico potente, que alude à vontade de combinação de muitas vontades, em que pese a multiplicidade real de planos em um universo social objetivo e o seu aspecto profundamente contraditório (AXT et al., 2011); e que vai se atualizando em microatos (de criação), tais como "isolar" e "extrair" detalhes quaisquer: duas operações de ordem estética, privilegiadas por Bakhtin (2002b), pelas quais a atenção contemplativa (mas ativa) é, a um só e mesmo tempo, atraída... distraída... traída...

Fractal, Rev. Psicol., v. 28 - n. 2, p. 231-241, 2016
Esses detalhes recortados de uma paisagem, ou de um objeto, que convocam a atenção contemplativa (estética), podemos considerá-los como uma espécie de pontos atratores de intensidade, o que é lembrado, tanto por Bakhtin (2002b), quanto por Guattari (1993), o segundo autor dando potência à perspectiva do primeiro, no escopo contemporâneo que realça o paradigma estético nas práticas sociais-coletivas de singularização. Esses detalhes, atratores da atenção contemplativa, quando retirados de seu contexto costumeiro e jogados para um novo plano (de virtualidades), podem reinventar, de modo surpreendente e inesperado, um novo/outro contexto composicional-relacional, pelas vizinhanças inéditas que sugerem.

Assim pode nascer, por exemplo, uma horta, que logo se reinventa em sítio de hortaliças, que logo se torna também um sítio de pomares e logo um sítio de vacas de leite, de cabras, de porcos, de galináceos: um sítio que precisa de agricultores (imigrantes?), que precisa de uma cultura rural (costumes?): um sítio que precisa de uma zona rural, que precisa de rios e lagos e campos e currais: que precisa de estradas e de transportes: que precisa de cidade, que precisa de leis, que precisa de legislador, de executor, de moradores: que precisam das políticas públicas, que precisam saber preservar o ambiente habitado por todos: que precisa de... educador/a para produzir in(ter)venções e problematizar o que se planta numa horta e como se planta, e para que se planta, e como e para que se cuida da plantação... ou como e para que se cuida da criação animal, ou... e como tudo isso vem parar em nossa mesa... e como tudo isso se transforma ou não em saúde: que precisa de... livros para buscar algumas respostas... que precisa de internet... que precisa de pais e de família para contarem as histórias da tradição do lugar: “- para atravessar o rio, a gente precisava de uma balsa, pois não tinha ponte!- o que é uma balsa? - vamos construir uma pra tua cidade" (interlocução entre um pai e um grupo de crianças). Aranzel!

Cada isolamento e extração inicial de uma imagem-objeto ou de uma imagem-paisagem podemos considerar, como no mundo de Gadda (CALVINO, 1990b), um nó complexo de partida à construção, ou um centro atrator (em potencial) de uma rede de relações. Pois, de qualquer ponto-centro ou nó de onde se parta, pelo próprio movimento em linhas, pelo qual é tomado o agenciamento, ele vai produzindo e alargando horizontes e se diversificando em novas maquinações, constituindo uma rede-linhas labiríntica e interconectada, uma cidade-rede em que nós (pontos-centros atratores) se espraiam em linhas.

[...] a própria Cidade vivida age como uma espécie de ponto intensivo, momentâneo e fugaz, podendo abrir à captura, sempre provisória, de forças e fluxos, durações e velocidades, formas e limites [...] É pela intensidade que é dado potencializar efeitos de sentido - incorporais -, os quais [...] devem encontrar condições de passagem para o nível da expressão [...] produzindo, a um só e mesmo tempo, linhas de fuga, com novas possibilidades [...] (AXT, 2004, p. 229-230).

Mas se a cidade-experimentação, enquanto dispositivo do agenciamento, se constitui nesta ambivalência ponto-linhas, também o próprio agenciamento coletivo (das 
crianças e educadora, imersas no contexto da sala de aula) devém cidade-ponto intensivo, recriando-se em linhas ético-relacionais de convivência coexistencial, assim como em linhas estético-criadoras de novos mundos imaginantes a reinventarem sensibilidade, pensamento, saberes.

As cidades-experimentações das crianças acionam uma linha da imaginação, fazendo-a vibrar em meio ao costumeiro, fazendo-a saltar em direção a outros horizontes, uma linha que articula em sua composição o heterogenético, avizinhando modos (que, entre si, são diferentes) de: pensar-conhecer (movimentando um devir-científico); pensar-combinar (movimentando um devir-artístico); e pensar-conceituar (movimentando um devir-filosófico); sem que se possam separar estes "modos de pensamento" tão bem pontuados por Deleuze e Guattari (1997).

Tirar valor à imaginação da infância em benefício de um "puro" cognitivo em sua seriedade lógica, separar um pretenso "subjetivo" de um almejado "objetivo" - "a cidade imaginária é interessante, mas não se pode esquecer que as crianças precisam estudar a cidade real!'... Enunciados como este, proferido num encontro de professores do Projeto Civitas, esbarram no alerta de Gadda (CALVINO, 1990b), para quem conhecer sempre é inserir algo no real, sendo portanto deformar o real!, numa aparente sugestão (para nós!) de que nossas realidades são sempre produzidas; e que a lógica que rege os saberes não é (não deveria ser), nem do "ou" exclusivo, nem da dialética em espiral, mas do "ou" inclusivo, do "e...e...e...", como lembram Deleuze e Guattari (2000), uma lógica que soma e potencializa, disposta a cartografar a teia relacional híbrida dos afectos e perceptos em meio a funções, a coordenadas e a conceitos.

Nesta perspectiva, conhecer e imaginar não se separam, conhecer pode girar em torno de (re)inventar relações, decompondo as costumeiras, já dadas que produzem fatos, objetos, coletivos, mundos segundo uma ótica estratificada, para recompô-las em meio a outras vizinhanças, outras misturas composicionais (apontando a uma estética da vida), cujas possibilidades de combinações podem surpreender, assim como Gadda e Bergson surpreendem: o primeiro, associando à literatura o conhecimento científico como método para extrair o literário; e o último, colocando em diálogo filosofia e ciência, do que deriva o estático da ciência como operação imaginária segunda (em relação ao filosófico), com vistas a driblar o movente da realidade em seu devir, este movente sendo condição (filosófica) primeira, para qualquer possibilidade de relação entre esses polos.

A cidade-rede, ao ampliar indefinidamente os pontos-centros atratores, enreda-se em seus próprios fios, tendo que aprender a lidar com a diversidade e com a multiplicidade, pois nestes agenciamentos das cidades-experimentações, há um coletivo maquínico em-relação, que não é da ordem do homogêneo: há uma rede, mas não há propriamente uma forma! A rede cresce em várias frentes simultaneamente: é ao mesmo tempo, que o sítio de hortaliças vira sítio de pomares e de vacas de leite... é ao mesmo tempo que se constroem as vias de comunicação entre as gentes e se estuda um pouco mais sobre meios de comu- nicação e de transportes... é ao mesmo tempo que se espia a cidade por uma janela e se veem as chaminés-paisagens e a flor-objeto... Há uma aceleração, nesses movimentos de simultaneidade do diverso, que tensiona continuamente com a lentidão dos movimentos de adensamento analítico e apreciativo em busca de consistência para os pontos-centros, ou nós, de onde derivam as relações em rede.

É na lentificação dos movimentos em busca do detalhe (na pesquisa de um item, na construção de um objeto, de uma ferramenta, na contação escrita ou oral de uma história-enredo) que a cidade se faz corpo: cidade-corpo! Extensão física a desdobrar-se num espaço até então vazio, cada edificação, cada rua, cada árvore faz corpo com o espaço, subjetivando-o, necessitando-se que o fluxo das ideias, em simultaneidade coexistente e contraditória, vá sendo demorado continuamente por corporificação...

Cidade-corpo que precisa o detalhe, que observa a nuance, que encaixa o menor no maior, que quer saber por que qualquer algo supõe algo outro: lentidões do corpo em tensão com as acelerações de um espírito que não olha para si, que olha à frente absorvido, que mira em outros universos da virtualidade, em outros horizontes: cidade-espírito!... É ao mesmo tempo que um corpo lento se desdobra em rede ampliada de horizontes, compondo ideias aceleradas em uma cidade-espírito; e se dobra em intensidades infinitamente pequenas, exercitando modos inesperados de morar nos fluxos moventes do pensamento criador, no que pode ser ajudado por minúcias, como as minúcias rítmicas de um martelo que prega um prego; ou por cadências, como as cadências sonoras que se despregam de um hino da cidade em processo de composição; ou por avatares minúsculos e perfeitos (quase!), corpos intensivos que apropriam e transfiguram poieticamente o próprio pequeno criador, que então imerge como personagem-avatar na cidade-experimentação. No contrafluxo, sobem à superfície as intensidades narrativas para serem historicizadas, cidade-linguagem: avatares-simulacros tomados pela cidade-corpo, atravessados por afecções e percepções que lutam para emergir como perceptos e afectos, cidade-intensiva, cidade-da-alma, lugar de passagem para as narrativas!...

\section{As cidades-experimentações como efeito-lugar-e-passagem}

Eis o que eu gostaria de saber a seu respeito; confesse o que você contrabandeia: estados de ânimo, estados de graça, elegias (CALVINO, 1990a, p. 93).

É ao mesmo tempo que uma cidade-corpo faz elo com a cidade-rede ou cidade-espírito, e com a cidade intensiva, a cidade-da-alma. E é enquanto cidade intensiva tomada pelos avatares-simulacros (que já há muito perderam a memória mimética, lançados que foram em devires criadores), que a cidade-corpo se transmuta, devindo cidade-lugar!

Cabe mencionar, na linha da diferença, o pensamento de Fuganti (1990, p. 61), com o qual nos deparamos, em meio à escrita: "Só o presente existe no tempo, porque é o presente dos corpos. Só os corpos ocupam um lugar no

Fractal, Rev. Psicol., v. 28 - n. 2, p. 231-241, 2016 
vazio e existem no tempo presente - no Cronos. Na relação do corpo com o vazio - incorporal puro -, vai emergir um efeito incorporal: o lugar".

Lugar do aqui-agora do espírito e das intensidades da alma, lugar onde o intensivo e o ideado têm licença para pousar e fazer morada, morada do sentido, amalgamando corpo, alma e espírito, lugar por onde circulam afecções e percepções, querendo devir perceptos e afectos na linguagem dos enunciados, em busca de mais e outros horizontes.

Deleuze e Guattari (1997) falam sobre perceptos e afectos como o que compõe blocos de sensações, transbordando percepções e afecções vividas/sentidas, descolando-se do vivido para adquirir autonomia (na arte, na linguagem...) e assim poder durar.

Ao mesmo tempo, a cidade quer-se "lugar" das afecções e percepções no aqui-agora e "passagem" para afectos e perceptos na linguagem verbal! Paradoxalmente, cidade-lugar-e-passagem, lugar de passagem! A cidade como lugar de passagem!!! Mas ainda assim uma cidade-lugar!!!

Lugar para morar, morada da vontade de acontecimento de um coletivo, acontecimento ético pronto a se espraiar criadoramente, enraizando-se no encontro com o espaço vazio e liso das plataformas de papelão e isopor; acontecimento da escuta, que vai ao encontro do outro, do estrangeiro, disposta a acolher o que difere, a sustentar o que não parece útil, a impulsionar o que quer ser imaginado, o que quer ser expresso, timidamente se mostrando em mistura inusitada com enunciações, estas sempre inconclusas, embora ciosas de acabamento... o que diz do contraditório na linguagem: sempre em falta do que restou ainda por dizer, mas também sempre em condição de completude enquanto unidade comunicativa, e que Bakhtin (1990) diz ser "plena". Acabamento e inacabamento constituem-se como princípios dinâmicos importantes, os quais regem o movimento complexo que institui uma relação de solidariedade entre ética e estética, na ótica bakhtiniana.

Cidade-lugar constitui-se no entrecruzamento cronotópico (espaço-temporal) da produção prolífera, e por vezes inusitada, de séries divergentes de sentido sempre em variação: lugar paradoxal do sentido, ao mesmo tempo de condensação (em nós intensivos) que dobra e enraíza; e de dispersão (em linhas enunciativas e em rede extensiva) que desdobra e foge; mas que também, de uma maneira ou outra, poieticamente se organiza em cronotopo que sustenta este sentido em variação, permitindo-lhe fazer morada. Cidade-lugar constitui-se como um amigo (intercessor) sempre aí, no tempo-duração de um período letivo, que abre passagem para o pensamento-espírito e para as intensidades da alma. Cidade-lugar, personagem (conceitual) singular, que instiga e incita à enunciação expressiva, fazendo descolar da recognição representacional.

\section{As cidades-experimentações e a narratividade criadora}

Mas quem me ouve retém somente as palavras que deseja. [...] Quem comanda a narração não é a voz: é o ouvido (CALVINO, 1990a, p. 123).
É como lugar de enraizamento, arrancado às lisuras e ao vazio do espaço, no longo encontro ético do tempo-durando, exercitado pela vontade de acontecimento de um coletivo, que se produzem lentamente condições de passagem para a instância da expressão enunciativa. É quando a cidade inquieta e desejante desse coletivo, a cidade em desassossego passa a operar como máquina imaginante, maquinando enunciados: cidade maquínica, agenciando os processos expressivos na linguagem-enunciação, que fazem habitar de modos diversos e multíplices as palavras, fazem rachar a ilusão de homogeneidade dos conceitos.... e instaurar e sustentar uma produção de sentidos por variação contínua.

$\mathrm{O}$ efeito é de multiplicidade na arte de usinar o pensamento criador, enlaçando-os a ambos - a imaginação narrativa e o conhecimento-saber em rede -, no interior do agenciamento: agenciamento ao mesmo tempo maquínico e de enunciação coletiva que produz a cidade-experimentação e suas narrativas. Um aranzel!!

Contudo, assim como ocorre com a cidade-sendo-edificada, as cidades-sendo-narradas não nascem expressivas logo de saída, nascem como podem, em meio ao senso comum dos sentidos costumeiros habitando palavras de ordem: só que, no caso da enunciação verbal, o espaço entre enunciados é não-vazio; apresenta-se, como sugere Bakhtin (1990), sempre já preenchido pela palavra.

Esta (a palavra), por sua vez e de maneira geral, apresenta-se desde logo estriada pelas tentativas que sofre, de congelamento dos traços nucleares da significação, seja devido à dicionarização (por necessidade mesmo de um comum que sustente a intercomunicação), seja em razão do discurso monológico dominante e regulador: ambos se esmeram em apagar a polissemia e a polifonia, as quais habitam a palavra como efeito da variação enunciativa, nos múltiplos contextos por onde a mesma circula. É, pela via do disciplinamento que estabiliza o sentido, que costumeiramente se institui o sentido autorizado, ou significado, que tanto pode insinuar-se pelo senso comum das palavras de ordem, quanto pelo moralismo do bom senso que aponta, por antecipação, a melhor ou mais verdadeira palavra.

Por outro lado, a novidade - se é que ela chega a se mostrar, fazendo avançar a intriga coletiva do enredado enunciativo - vai também sendo usinada, num intervalo: só que, então (pensamos poder identificar!), este intervalo não estaria mais dizendo respeito a um espaço entre enunciados, mas a um intervalo de tempo-duração no entre das enunciações em curso!

Aqui queremos colocar em diálogo autores como: Bakhtin (2003), que empresta valor emocional axiológico às entonações das vozes enunciativas que se encontram em relação, no fluxo enunciativo-comunicacional contínuo e movente da linguagem, e que tem no enunciado (de conceituação ampla e flexível, que comporta desde uma palavra até um livro ou uma época) sua unidade dinâmica de apreciação critica; e Bergson (1990, 2006), que entende o presente como um corte que situa o corpo e suas afetações no atual, sendo a emoção ou afec- 
ção, justamente o que preenche este intervalo constituído pelos cortes, que descontinuam o tempo na duração; e Deleuze e Guattari (1997, p. 204), que traduzem este intervalo como entretempo, alojando o acontecimento, pois "quando o tempo passa e leva o instante, há sempre um entretempo para trazer o acontecimento".

É, então, no tempo-duração do agenciamento enunciativo, em meio a um jogo disparatado de forças, que o sentido emerge, fazendo carregar as entonações, marcas da emoção em modo apreciativo de acento de valor.

À novidade (inusitada, inesperada), apraz-lhe instalar-se em meio à heterogeneidade enunciativa; e na mesma proporção e importância em que esta (a heterogeneidade) se faz presença! $O$ inusitado pode ser tanto maior (até pelo seu descabimento! como quando a criança dispara que o "que está faltando na cidade é uma zona"), quanto maior for a diferença entre as enunciações e os seus enunciados (aquilo que foi enunciado em relação de tensão) num determinado momento linguageiro (sugerindo múltiplas vozes e línguas em confronto). Um rolo! Um aranzel!

Acolher o heterogêneo, o estranho, o que difere nas enunciações e seus enunciados, mesmo o que parece não-senso, pode diluir as estrias do senso comum e do bom senso acomodadas em modo palavra, abrindo à virtualização do já dado, do já dito das realidades em curso, com isso tornando o tempo intervalar no entre das enunciações, em zona de valor entonacional em devir, zona engravidada de emoções, sensações se anunciando: zona algo indiscernida quanto ao sentido a emergir, zona habitada por muitos acentos apreciativos de valor (uma polissemia criadora do virtual), por muitas vozes (uma polifonia um tanto estrepitosa e relativamente desafinada), muitas línguas (um multilinguismo que, ainda e sempre, não se entende muito bem entre si, deixando aparecer as gagueiras).

Bakhtin (1990, 2002b), Deleuze (1997) e Guattari (1993) estão em acordo (o suficiente!) quanto à potência criadora das acentuações valorativas, das desafinações e das gagueiras nascidas em meio ao heterogêneo multilíngue, multivocal-polifônico.

É então, neste tempo intervalar - zona de indeterminação entre instantes enunciativos marcados por enunciados -, em meio ao apreciativo gaguejante e desafinante das enunciações em luta (e justamente por causa da diversidade de emoções presentes, em jogo de forças), que o acontecimento do sentido (inusitado, novidadeiro) tem licença para se instalar, emergindo nesse pequeno intervalo de encontro e confronto entre sentidos: um sentido que devém enunciação, ao querer se apresentar como um expresso no enunciado-que-narra-a-cidade.

Este sentido-acontecimento da vida em ato, no seu-acontecendo em meio ao coletivo de enunciações, precisa furar a barreira da linguagem e se instalar no enunciado (não é trabalho pouco!!), pois ao mesmo tempo, é sentido estrangeiro, que não concerne ao enunciado, propriamente: microato (frágil!) de criação, que antes diz respeito ao estado de coisas no processo da vida-acontecendo, à emoção e aos valores apreciativos que dela derivam em relação de tensão, e dos quais o enunciado fala. Deleuze (1998, p. 132) nos conduz a pensar assim! Mas também Bakhtin (1990), que ainda sublinha: "sem acento apreciativo não há palavra".

Então, se o sentido emerge indomável em meio à mise-en-scène enunciativa, numa relação de intimidade exuberante com a vida em sua eventicidade (na cidade-experimentação), fazê-lo (ao sentido) instalar-se no enunciado narrativo requer o ato criador de um sujeito de linguagem, habitando um agenciamento coletivo de enunciação.

O sentido-acontecimento, nas experimentações narrativas, diz respeito, então, a algo das intensidades afectivas-perceptivas que atravessam o corpo, e que se dobram com o espaço-se-fazendo da cidade, seus eventos e seus horizontes, com as edificações que "inventam memórias" (para lembrar Manoel de Barros, 2010) e as enraízam, criando o lugar: lugar de multiplicidades que anuncia o sentido-acontecimento no tempo intervalar interenunciativo, sentido anunciado que precisa subir à superfície tensa do linguageiro para ser enunciado.

A potência enunciativa (no contexto amplo das linguagens, não somente a verbal) nos aparece transitiva, sendo esta transitividade - entre o gesto, o olhar, a escuta e a voz (AXT, 2006) - que torna a cidade-sendo-edificada em cidade-sendo-narrada; e que transfigura o espaço praiano estriado pelas memórias (inventadas), em tempo intervalar indiscernido no entre-entonacional das enunciações.

Só que operar esta transfiguração de espaço (vazio, inicialmente) em tempo (intervalar indeterminado, ao "final"), requer confrontar e atravessar: primeiro, o espaço tornado estriado das edificações da cidade, devindo-as memórias (inventadas); e segundo, o espaço entre enunciados, onde se encontra acomodada a palavra estriada do cotidiano (estável e autoritária), tornando-a flexível e aberta aos devires do sentido. Isso não se faz sem susto! o da estupefação contemplante; nem sem custo! o da refração do sentido, engendrando o "gesto de interpretação" (BAKHTIN, 1990).

Estamos explorando aqui a noção de refração de Bakhtin (1990, p. 45-47), para quem a linguagem integra a realidade, na esfera ideológica (das ideias), e a palavra, não somente reflete as sutilezas da existência social, mas também refrata o que nela se reflete, em meio a um jogo de ocultações e descobertas orquestrado pelos confrontos de interesses sociais contraditórios. Por nossa parte, contudo, não nos interessa pensar a refração numa acepção de manipulação dos sentidos por um estrato (que, no contexto bakhtiniano é o das classes dominantes; e que aqui temos indicado pela via das palavras de ordem), mas acentuar a produção aberta de sentido no encontro e confronto de forças entre enunciações, gestando a interpretação. A interpretação é tomada no sentido bakhtiniano de "gesto de interpretação", fortemente aderente a uma pragmática (não um pragmatismo) das interações (das relações do agir) que se fazem em contexto de realidade, em meio às quais se realizam os enunciados. 
A transitividade (do sentido) entre linguagens não é direta, natural, ou sem gagueiras, sem desafinações: tal exige esforço de estranhamento ou de reconhecimento de uma estrangeiridade. Neste fluxo processual de uma experimentação com diferentes linguagens e confrontos entre vazios e cheios, há, a um só tempo: (i) perdas... pois, não há como dar conta, no seu todo, dessa transposição, mediante uma tradução literal (ou automática); (ii) e ganhos... assim como sempre se insere algo de novo no real, para conhecer - como adverte Gaddda (CALVINO, 1990b) e que Bergson (2006) dirá ser da ordem da afecção, que permeia a percepção -, sempre se insere algo de novo na tradução, deformando-a: essa deformação ou refração se dá, não apenas como efeito do manuseio de outra materialidade, mas principalmente porque implica o sentido estrangeiro que aí se instala pedindo passagem. A esse manuseio que produz a refração ou deformação, queremos chamar gesto. E a essa tradução refratada ou deformada, queremos chamar de gesto de interpretação.

Muito particularmente, então, queremos considerar que o gesto de interpretação, quando insere algo novo na tradução, deformando-a, está, antes de tudo, acolhendo uma produção (entonacional) de sentido, o qual emerge deste tempo intervalar interenunciativo e coletivo e quer ser enunciado, enquanto efeito do que aí se encontra em tensão: as emoções e seus acentos apreciativos de valor, mas tanto uns quanto outras, entrançados às memórias inventadas da cidade-corpo-lugar; misturados às memórias imaginantes, que maquinam o devir-cidade e entoam as enunciações.

O gesto de interpretação, pela refração operada pelo sentido que devém enunciação, transfigura-se, assim, no que chamamos de microato de criação: gesto que aninha o sentido-acontecimento, produzindo a narrativa; cidade-narrativa, que se tece singular por entre os sentidos-acontecimentos, emergindo do entremeio (coletivo) das enunciações como efeito de autoria (precária e provisória).

Dessa mistura enunciativa composicional heterogênea, que cava os intervalos entre a cidade-corpo, a cidade-espírito e a cidade-da-alma, nasce o sentido-acontecimento que alimenta as narrativas, maquinação desejante usinando sua expressividade. É neste tempo intervalar, indiscernido, das enunciações que não coincidem, que se reinstalam as intensidades afectivas e perceptivas, já antes instauradoras de sentido no âmbito das cidades-sendo-edificadas, enquanto estado de coisas: sentidos em arranjos polissêmicos e contraditórios que se encontram, se confrontam, tensionando o gesto de interpretação pela vontade de tradução, que se fará expressivo na inflexão narrativa, buscando, não sem dificuldades, um estilo, marca de singularidade do agenciamento.

De um devir-intérprete que, pelo gesto de interpretação (no entremeio enunciativo), acolhe o sentido em sua estrangeiridade, nasce um devir-autor (gaguejante e desafinante), cuja enunciação devém singular no encontro com este estranho do sentido que aí se instala: uma enunciação (narrativa) em vias de produzir um estilo; enunciação-morada para a estrangeiridade enquanto marca do que difere no enunciado; sentido-acontecimento, na fronteira entre o agenciamento maquínico das cidades-sendo-edificadas e o agenciamento coletivo de enunciação das cidades-sendo-narradas, instigando o devir-autor... Um devir-autor que, pela vontade de acontecimento, engendra-se no modo "autoria coletiva"; autoria que, ao expressar-se narrativamente, compromete-se com o expresso, responsabiliza-se pelo dito, pelo narrado, pelo escrito.

Axt (2004, p. 225) trabalha a noção de autoria como posições fugazes de interpretação, forçando a função-autor, salientando que não há um diferir absoluto, dado de uma vez para sempre; que o diferir só se faz na duração (no tempo), ao mesmo tempo, e pela mesma relação ao que já é. Por outro lado, Axt e Elias (2003) recuperam e ampliam a noção de autoria coletiva que se encontra já em Axt e Maraschin (1999), esclarecendo que a mesma diz respeito às posições ocupadas pelos sujeitos na assunção da função de autoria, as mais diversas, impossíveis de serem determinadas, constituindo intersecções na forma de um nó rizomático, compondo infinitos pontos de cruzamento... posições comprometidas com a produção de sentido numa dimensão simultaneamente ético-estética, coletivo-singularizante, constituídas nos entrelaçamentos advindos das conexões produzidas a partir de relações de tensão geradas na multiplicidade disjunta e heterogênea de enunciados em cruzamento, entrecruzados (AXT; ELIAS, p. 261-275).

Bakhtin (2012) lembra, com relação a um agir (sempre autoral-interpretativo, pelas tomadas de posição que implica), que não há álibi na vida em seu-acontecendo, é preciso responsabilizar-se, assinar. É a assinatura que se corresponsabiliza pelo ato ético (e político) da vontade de acontecimento, e que garante esta posição enunciativa singular em processo de ser, de ser cidade, cidade narrativa... a qual faz ressoar, nas franjas da expressividade, o sentido-acontecimento, atualizando aprendizagens em sua máxima potência possível como certo estilo!

Esta perspectiva, a um só tempo estética e ética, reverbera uma política de pesquisa e formação que se propõe a sustentar (no campo educativo) o inusitado (infantil) no entre das enunciações. Como enfatizado em Axt (2014, p. 20-22), pensa-se em uma escuta do educador cuja atenção não esteja tão concentrada no foco conteudístico em pauta, mas cuja atenção, intencionalmente distraída (num sentido bergsoniano, de não estar comprometida apenas com o que é útil da ótica de um programa curricular, mas de também associar-se à alegria de pequenas fruições contemplativas), possa capturar aqui ou ali eventuais inusitados. A autora ainda pontua que esses inusitados, ao serem isolados em relação ao contexto original, e jogados em direção a novos contextos enunciativos-imaginativos, estão abrindo à experimentação de práticas (docentes) inventivas, fazendo nascer os "projetos de criação coletiva e acolhimento à diferença", como este das cidades-experimentações. Práticas inventivas, ao deixarem passar, por entre as linhas duras do cotidiano costumeiro algo dos fluxos criativos instituintes de um aprender enquanto acontecimento, alçam crianças e educadores a posições enunciativas transitoriamente autorais: devir-autor marcado pela responsabilidade do dizer 
na relação de mútua afetação com o escutar; devir-autor voltado às expressividades enunciativas criadoras de novas processualidades existenciais.

\section{Referências}

AXT, M. Civitas a cidade viva ou de um espaço para o acontecimento-invenção na escola. Educação e Realidade, Porto Alegre, v. 29, n. 2. p. 219-235, 2004.

AXT, M. Comunidades virtuais de aprendizagem e interação dialógica: do corpo, do rosto e do olhar. Filosofia Unisinos, São Leopoldo, v. 7, n. 3, p. 256-268, set./dez. 2006.

AXT, M. Por uma escuta dos sentidos na maturidade-velhice. In: OUTEIRAL, J. et al. (Org.). Amadurecer: ensaios sobre o envelhecimento. Curitiba: Maresfield Garden, 2013.

AXT, M. Imaginar... Aprender... O Projeto Civitas e a pequena porta por onde passa Alice. In: SILVEIRA, P. D.; AXT, M.; HINTERHOLZ, B. (Org.). Imaginar e aprender na Educação Infantil: Projeto Civitas. Porto Alegre: Paiol/Leitura XXI, 2014. p. 13-23.

AXT, M. et al. Interdisciplinaridade na ótica do Programa de Pós-Graduação em Informática na Educação da UFRGS. In: PHILIPPI JR., A.; SILVA NETO, A. J. (Ed.). Interdisciplinaridade em Ciência Tecnologia e Inovação. Barueri: Manole, 2011. p. 629-646.

AXT, M.; ELIAS, C. R. Autoria coletiva ambientes virtuais e formação. In: MARASCHIN, C.; FREITAS, L. B. L.; CARVALHO, D. C. (Org.). Psicologia e Educação: multiversos sentidos, olhares e experiências. Porto Alegre: UFRGS, 2003. v. 1 , p. $259-277$.

AXT, M.; KREUTZ, J. R. Sala de aula em rede: de quando a Autoria se (Des)dobra em Inter(ven)ção. In: FONSECA, T. M. G.; KIRST, P. G. Cartografias e devires: a construção do presente. Porto Alegre: UFRGS, 2003. p. 319-339.

AXT, M.; MARASCHIN, C. Narrativas avaliativas como categorias autopoéticas do conhecimento. Revista de Ciências Humanas, Florianópolis, p. 21-42, 1999.

AXT, M.; MARTINS M. A. R. Coexistir na diferença; de quando a formação em serviço pensa modos de habitar a sala de aula. In: TRINDADE, I. M. F. (Org.). Múltiplas alfabetizações e alfabetismos. Porto Alegre: UFRGS, 2008. p.133-158.

BAKHTIN, M. Marxismo e filosofia da linguagem: problemas fundamentais do método sociológico na ciência da linguagem. 5. ed. São Paulo: Hucitec, 1990.

BAKHTIN, M. Problemas da poética de Dostoievski. Rio de Janeiro: Forense Universitária, 2002a.

BAKHTIN M. Questões de Literatura e Estética: a teoria do romance. 5. ed. São Paulo: Hucitec/Annablume, 2002b.

BAKHTIN, M. Estética da criação verbal. 4. ed. São Paulo: Martins Fontes, 2003.

BAKHTIN, M. Para uma filosofia do ato responsável. 2. ed. São Carlos, SP: Pedro e João, 2012.

BAREMBLITT, G. Compêndio de Análise Institucional $e$ outras correntes: teoria e prática. Rio de Janeiro: Rosa dos Ventos, 1998.

BARROS, M. de. Memórias Inventadas: as infâncias de Manoel de Barros. São Paulo: Planeta do Brasil, 2010.

BAUM, L. F. O Mágico de Oz. Porto Alegre: L\&PM, 2001.
BERGSON, H. Matéria e memória: ensaio sobre a relação do corpo com o espírito. São Paulo: Martins Fontes, 1990.

BERGSON, H. O pensamento e o Movente: ensaios $e$ conferências. São Paulo: Martins Fontes, 2006.

CALVINO, I. As cidades invisiveis. São Paulo: Companhia das Letras, 1990a.

CALVINO. I. Seis propostas para o próximo milênio. São Paulo: Companhia das Letras, 1990b.

COSTA, L. O corpo das nuvens: o uso da ficção na Psicologia Social. Fractal: Revista de Psicologia, Niterói, v. 26, n. esp., p. 551-576, 2014.

DELEUZE, G. O mistério de Ariana. Lisboa: Passagens, 1996.

DELEUZE, G. Crítica y Clínica. Barcelona: Anagrama, 1997.

DELEUZE, G. A lógica do sentido. São Paulo: Perspectiva, 1998.

DELEUZE, G. Espinosa: filosofia prática. São Paulo: Escuta, 2002.

DELEUZE, G.; GUATTARI, F. O que é Filosofia? Rio de Janeiro: Ed 34, 1997.

DELEUZE, G.; GUATTARI, F. Mil platôs: capitalismo e esquizofrenia. Rio de Janeiro: Ed 34, 2000.

DIAS, R. O. Imaginar. In:FONSECA, T. M. G.; NASCIMENTO, M. L.; MARASCHIN, C. (Org.). Pesquisar na Diferença: um abecedário. Porto Alegre: Sulina, 2012. p. 127-130.

FUGANTI, L. A. Saúde, Desejo e Pensamento. In: CAMPOS, F. B.; LANCETTI, A. (Org.). SaúdeLoucura: experiências da reforma psiquiátrica. São Paulo: Hucitec, 1990. v. 2, p. 19-82.

FUGANTI, L. A. Devir. In: FONSECA, T. M. G.; NASCIMENTO, M. L.; MARASCHIN, C. (Org.). Pesquisar na Diferença: um abecedário. Porto Alegre: Sulina, 2012. p.7579.

GUATTARI, F. Caosmose: um novo paradigma estético. São Paulo: Ed 34, 1993.

KREUTZ, J. R. Resistir, problematizar e experimentar como desdobramentos do aprender. 2009. Tese (Doutorado)Programa de Pós Graduação em Educação, Universidade Federal do Rio Grande do Sul, Porto Alegre, 2009.

KRUG, M. Pelas trilhas do Civitas: experimentações e vivências numa prática pedagógica investigativa. In: TRINDADE, I. M. F. (Org.). Múltiplas Alfabetizações e Alfabetismos. Porto Alegre: UFRGS, 2008. p. 159-180.

LAZZAROTTO, G. D. R. Experimentar. In: FONSECA, T. M. G.; NASCIMENTO, M. L.; MARASCHIN, C. (Org.). Pesquisar na Diferença: um abecedário. Porto Alegre: Sulina, 2012. p.101-103.

MARTINS, M. A. R. Projeto Civitas: (multi)(pli)cidades e as interveRsões do tempo na sala de aula: ensino fundamental. 2009. Tese (Doutorado)-Programa de Pós Graduação em Educação, Universidade Federal do Rio Grande do Sul, Porto Alegre, 2009.

REMIÃO, J. A. A.; SILVA, P. M. da; AXT, M. Cidades narradas: dispositivo dialógico para uma estética das relações no campo da pesquisa-formação. In: HETKOWSKI, T. M.; MÜLLER, D. N.; AXT, M. (Org.). Cultura Digital e espaço escolar. Salvador: EDUNEB, 2014. p.155-178. 
SELLI, M. S.; AXT, M. Formação de professores: produzindo inclusão digital e aprendizagem numa perspectiva (est)ética. In: HETKOWSKI, T. M.; MÜLLER, D. N.; AXT, M. (Org.). Cultura Digital e espaço escolar. Salvador: EDUNEB, 2014. p. 233-254.

SILVEIRA, P. D. O que fazemos enquanto grupo de professores abertos ao aprender. In: SILVEIRA, P. D.; AXT, M.; HINTERHOLZ, B. (Org.). Imaginar e aprender na Educação Infantil: Projeto Civitas. Porto Alegre: Paiol/Leitura XXI, 2014. p. 25-29.

SOUZA, K. C. de O. Ressonância de uma Ética da Escuta: no entremeio da formação docente e sala de aula. 2013. Dissertação (Mestrado)-Programa de Pós Graduação em Educação, Universidade Federal do Rio Grande do Sul, Porto Alegre, 2013.

Recebido em: 16 de março de 2015

Aceito em: 6 de dezembro de 2015 